\title{
ZASTOSOWANIE POCHODNYCH CHINOLINY DO DEZYNFEKCJI DRUKÓW BIBLIJNYCH Z KOLEKCJI BIBLIOTEKI FUNDACJI WIKTORA H. BAWOROWSKIEGO WE LWOWIE
}

\section{Streszczenie}

Badania mikrobiologiczne i dezynfekcję przeprowadzono na XVI-wiecznej Biblii wydanej przez Jakuba Wujka, zgodnie z zapisaną sygnaturą CT II 75938 pochodzącej z Biblioteki Fundacji Wiktora h. Baworowskiego we Lwowie. Jakub Wujek był polskim duchownym, jezuitą, doktorem teologii, rektorem Akademii Wileńskiej. Przekład jego Biblii na język polski rozpoczął w latach 1584-1595, który w całości został wydany w 1599 roku Za życia J. Wujka został opublikowany tylko Nowy Testament oraz Psałterz (1594). Stary Testament był gotowy w 1596 roku Jakub Wujek zmarł w Krakowie 27 lipca 1597 roku, Biblia zaś ukazała się dopiero 25 sierpnia 1599 roku, bowiem Stanisław Grodzicki wraz z powołaną komisją doprowadził do zmian tekstu przekładu. Z uwagi na różne okoliczności i trudności dzieło J. Wujka pozostawało w Kościele katolickim najważniejszym przekładem Biblii przez ponad 350 lat.

Przed przystąpieniem do badań mikrobiologicznych przeprowadzono badania $\mathrm{pH}$ papieru. Wartość zmierzonego $\mathrm{pH}$ świadczy o niewysokim zakwaszeniu. Przeprowadzono badania mikrobiologiczne i stwierdzono, że zakażenie mikrobami nie jest równomiernie zlokalizowane. Najwięcej kolonii wyrosło na szalkach, w których umieszczono próbki pobrane z wyklejki lub karty tytułowej, a znacznie mniej ze środka bloku książki.

Wyizolowane z książki grzyby zidentyfikowano do gatunku. W badanej kolekcji stwierdzono występowanie Aspergillus Niger van Tieghem. Celem eksperymentu było syntetyzowanie nowych związków pochodnych chinoliny i wyznaczenie ich odpowiednich stężeń do zwalczania zagrożeń mikrobiologicznych występujących w Biblii J. Wujka. Do badań zastosowano

* Agnieszka Bangrowska - dr n. chem.; Instytut Bibliotekoznawstwa i Informacji Naukowej; Zakład Ochrony i Konserwacji Zbiorów Bibliotecznych; Uniwersytet Śląski w Katowicach; e-mail: bakalarzadr@poczta.onet.pl

https://orcid.org/0000-0002-5151-7099 
pochodne chinoliny. Liniowy wzrost grzyba monitorowano co 24 godziny, aż do całkowitego porośnięcia szalki kontrolnej, zawierającej zestaloną pożywkę $\mathrm{z} 1 \mathrm{~cm}^{3}$ roztworu DMSO. Zależność efektywności działania pochodnych chinoliny od zastosowanej dawki przedstawiono na wykresie w stosunku Aspergillus Niger van Tieghem. Przygotowano preparat do dezynfekcji zbiorów. Związki pochodne chinoliny to skuteczne, bezpieczne związki w dezynfekcji zbiorów bibliotecznych.

Słowa kluczowe: biblia; dezynfekcja; nowe związki; konserwacja; ochrona zbiorów

\section{Wprowadzenie}

Dezynfekcja zabytkowych zbiorów bibliotecznych jest ważnym elementem w konserwacji obiektów zainfekowanych przez drobnoustroje. Wszelkie prace konserwatorskie przeprowadzane na księgozbiorach musi poprzedzać ich odkażenie. Najczęstszym kolonizatorem zabytków bibliotecznych są grzyby oraz pleśnie, rzadziej bakterie. Powodują one wiele negatywnych zmian, prowadząc w konsekwencji do całkowitego zniszczenia zainfekowanych obiektów ${ }^{1}$. Obecnie stosowane środki nie zapewniają wystarczającej skuteczności oraz niosą ze sobą znaczne ryzyko dla personelu. Niska efektywność oraz krótki czas działania stosowanych substancji grzybobójczych zmuszają do okresowego powtarzania zabiegów, co negatywnie odbija się na kondycji papieru. Ponadto przyczynia się to do powstawania szczepów odpornych na stosowane środki ${ }^{2}$. Badania mikrobiologiczne i dezynfekcję przeprowadzono na XVI-wiecznej Biblii wydanej przez J. Wujka, zgodnie z zapisaną sygnaturą CT II 75938 pochodzącej z Biblioteki Fundacji Wiktora h. Baworowskiego we Lwowie. Opis bibliograficzny: Psalterz Dawidow / Teraz z Łacińskiego, z Graeckiego y z Zydowskiego na Polski ięzyk z pilnością przełożony y Argumentami, y Annotacyami objaśniony / Przez D. Iakuba Wvyka... - W Krakowie : W Drukarni Andrzeia Piotrkowczyka, 1594. - [1] leaf, 26 pp. [2] leaves, 283 pp., [8] leaves : il. ; 4References: E XV,7677 (Dawid); W 609; PK 1186 (Psalterium); Horoku 174 (Psalterium). BPW 285 (Psalterium); Boh. 1999 (Psalterium); BUP 249; BJP XVI 210; BLC 29,280; BUW XVI 1182; BNPOL;HPB; NUKAT; KVK: BnF; COPAC, OCLC, Worldcat; BASE: DBC Provenance: 1. Pro praedicatore Socalien[sis], title page, ink, 1617th c. 2. Pro loco Socaliensi ad Beatiss[imae] Virginis nostri consolationis title page, ink, 17th c. 3. ZCz [exl.] 4. WFB [stamp] 5. WB [stamp] 6. BS [stamp] Binding: cardboard, the parchment tinted red, 17 th-18th c.

${ }^{1}$ A. Bakalarz, Pochodne chinoliny jako nowe kolejne w badaniu fungicydy do dezynfekcji materiatów bibliotecznych $i$ archiwalnych, „Forum Bibliotek Medycznych”, 10 (2017) nr 2 (20), s. $165-170$.

${ }^{2}$ A. Bakalarz, Zagrożenia mikrobiologiczne zbiorów bibliotecznych, „Nowa Biblioteka”, (2014) nr 1 (14), s. 165-170. 


\section{Jakub Wujek i przeklady biblijne}

Jakub Wujek był jezuitą, polskim duchownym, doktorem teologii oraz rektorem Akademii Wileńskiej. Studiował filozofię, matematykę i język grecki na Akademii Krakowskiej i w Wiedniu, uzyskując tam wyższe wykształcenie magisterskie. Następnie podjął studia w jezuickim Collegium Romanum, gdzie studiował teologię i język hebrajski, uzyskując tytuł doktora. Po powrocie z Rzymu przyjął święcenia w 1568 roku i do 1571 roku był profesorem retoryki, katechetą i kaznodzieją konwentu w Pułtusku, a następnie rektorem kolegium w Poznaniu, Wilnie i Siedmiogrodzie ${ }^{3}$.

Mimo licznych obowiązków i podróży zaczął tłumaczyć fragmenty Biblii na język polski, wykorzystując świetną znajomość łaciny, greki, niemieckiego czy węgierskiego. Kongregacja prowincjalna w Kaliszu w 1584 roku zleciła mu przekład całej Biblii na język polski. Władze zakonne żądały od niego przekładu: „któryby y własnością y gładkością Polskiej mowy z każdym przyszłym zrównał, y prawdą a szczyrością wykładu wszystkie inne celował". Od J. Wujka oczekiwano więc przekładu, który przewyższy prace protestantów ${ }^{4}$. Należy nadmienić, że korzystał on z przekładów protestanckich - szczególnie pod względem językowym. Jezuita zachował stare wyrażenia i dawną terminologię religijną, odrzucając: „sprośności słów nowości, terminy starym chrześcijanom niesłychane, które nowowiernicy wznoszą, aby z kościołem katolickim zgoła nic spólnego niemieli"’.

Ks. Jakub Wujek przekład Biblii na język polski rozpoczął w latach 15841595, który w całości został wydany w 1599 r. Dnia 20 kwietnia 1593 roku napisał przedmowę do własnego przekładu Nowego Testamentu na język polski, co zyskało wielkie uznanie i zostało docenienie, ponieważ w roku następnym ukazało się już jego drugie wydanie. Ostre wymagania soboru trydenckiego (1545-1563) pozwalały tłumaczyć „Pismo Święte wyłącznie z łacińskiej Vulgaty, a przy uwzględnieniu wszystkich wad Vulgaty odsunięcie thumacza od tekstów oryginalnych stanowiło ewidentnie dalsze źródło niewierności przyszłego przekładu" . Stąd komisja jezuicka z księdzem S. Grodzickim na czele nakłaniała J. Wujka do naniesienia poprawek, czyli usunięcia wszelkich zwrotów od tekstu Wulgaty. Ks. doktor nie wyraził na to zgody i cały jego przekład nie został wydany ${ }^{7}$ „Sam Wujek stosował wiele własnych «słowotworów», oczywista odbiegających od dosłownego znaczenia tłumaczonych przezeń określeń, czyniąc jego przekład dalece innym niż dokładny. Wujek używał np. takich terminów jak «widosen» (widzenie, sen), czy «walecznik» na określenie żołnierza". Za życia jezuity ukazał się tylko Nowy Testament oraz Psałterz (1594). Stary Testament był gotowy w 1596 roku. Ks. J. Wujek w Krakowie 27 lipca 1597 roku, Biblia zaś ukazała się dopiero 25 sierpnia 1599 roku, S. Grodzicki bowiem doprowadził

${ }^{3}$ M. Kossowska, Biblia w języku polskim, t. 1, Poznań 1968, s. 323.

${ }^{4}$ Biblia Jakuba Wujka, https://pl.wikipedia.org/wiki/Biblia_Jakuba_Wujka/(dostęp 23.06.2019).

${ }^{5}$ Biblia Jakuba Wujka, http://biblia.tm.pl/biblia_jakuba_wujka.html/ (dostęp 23.06.2019).

${ }^{6}$ Biblia Szymona Budnego, (http://biblia.tm.pl/biblia szymona budnego.html/ (dostęp 23.06.2019).

${ }^{7}$ Biblia Jakuba Wujka, http://biblia.tm.pl/biblia_jakuba_wujka.html/ (dostęp 23.06.2019).

${ }^{8}$ Jezuici, http://www.madel.jezuici.pl/biblia/Biblia.html/ (dostęp 23.06.2019). 
do rewizji tekstu przekładu, którego tekst został zmieniony przez pięcioosobową komisję, $\mathrm{z}$ nim na czele ${ }^{9}$. Z uwagi na różne okoliczności i trudności dzieło J. Wujka pozostawało w Kościele katolickim najważniejszym przekładem Biblii przez ponad 350 lat $^{10}$.

\section{Charakterystyka zniszczeń}

Biblia była w niezłym stanie fizycznym. Skórzany grzbiet książki był dobrze przyklejony do grzbietu. Skóra na tylnej i przedniej okładzinie na krawędziach była przetarta, a lico zachowanej skóry częściowo wytarte z miejscowymi ubytkami (fot. 1). Szycie książki było zachowane w dość dobrym stanie. Karta tytułowa dobrze trzymała się bloku książki (fot. 2). Na kartach i na wyklejce były widoczne liczne zabrudzenia i zaplamienia, a także rozdarcia (fot. 3,4 ).

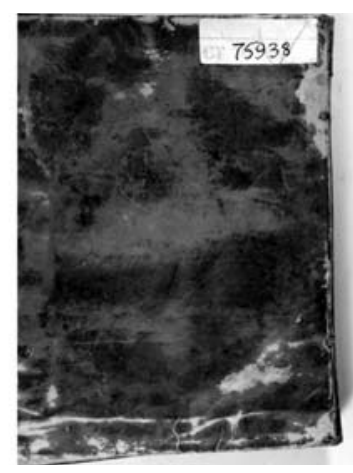

Il. 1. Widok okładki biblii (fot. autora).

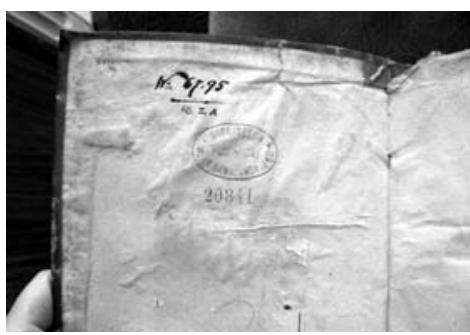

Il. 3. Strona wewnętrzna okładziny tylnej (fot. autora).

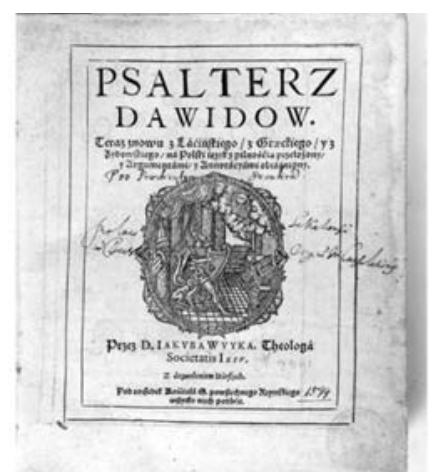

I1. 2. Strona tytułowa (fot. autora).

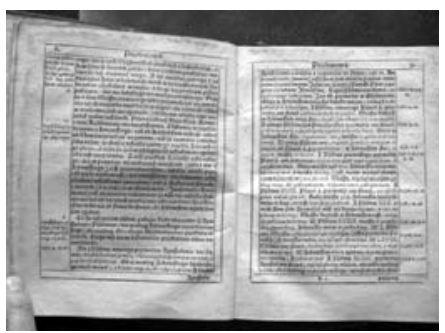

Il. 4. Zaplamienia na kartach książki (fot. autora).

\section{Stopień zakwaszenia księgozbioru}

${ }^{9}$ M. Majewski, Jak przeklady zmieniaja sens Biblii... O teorii i praktyce thumaczenia Biblii, https://upjp2.academia.edu/MarcinMajewski/ (dostęp 23.06.2019).

${ }^{10}$ Biblia Jakuba Wujka, http://biblia.tm.pl/biblia_jakuba_wujka.html/ (dostęp 23.06.2019). 
Przed przystąpieniem do badań mikrobiologicznych przeprowadzono badania $\mathrm{pH}$ papieru, licząc co trzecią kartę, i zbadano w trzech punktach pomiarowych. Dwa punkty pomiarowe były zlokalizowane w narożnikach karty, a jeden w środku.

Oznaczenie odczynu papieru wykonywano metodą kontaktową $\mathrm{z}$ wykorzystaniem na $\mathrm{pH}$-metru Elmetron CX-741, z elektrodą zespoloną EPX-3 $\mathrm{z}$ opcją automatycznego ustalenia końca pomiaru ${ }^{11}$. Stopień zakwaszenia zbioru przedstawiono w tabeli 1. Badana Biblia jest nieznacznie zakwaszona. Wartość zmierzonego $\mathrm{pH}$ świadczy o niewysokim zakwaszeniu. Niższą średnią wartość $\mathrm{pH}$ zaobserwowano na stronach początkowych, natomiast im dalej początku, tym średnia wartość pH wzrastała i wynosiła powyżej pH 6,0.

Tabela 1. Wartości pH papieru przed dezynfekcją

\begin{tabular}{|l|c|c|c|c|}
\hline & \multicolumn{4}{|c|}{ Wartość pH } \\
\hline Papier & & & & Średnia \\
\hline Karta tytułowa & 5,50 & 5,40 & 5,55 & $\mathbf{5 , 4 8}$ \\
\hline Karta 30 & 5,80 & 5,90 & 5,95 & $\mathbf{5 , 8 8}$ \\
\hline Karta 100 & 5,90 & 5,95 & 6,01 & $\mathbf{5 , 9 5}$ \\
\hline Karta 200 & 6,20 & 6,15 & 6,25 & $\mathbf{6 , 2 0}$ \\
\hline Karta ostatnia & 6,15 & 6,10 & 6,0 & $\mathbf{6 , 1 0}$ \\
\hline
\end{tabular}

Źródło: opracowanie własne.

\section{Ocena mikrobiologiczna}

Ocenę stopnia zagrożenia mikrobiologicznego wykonano z miejsc, które wykazywały wyraźne ślady obecnościżywej grzybni, czyli wszelkie przebarwienia, naloty, zacieki czy występujące deformacje. $Z$ wszystkich miejsc pobrano dwie próbki mikrobiologiczne. Pierwsza pochodziła z przedniej wyklejki lub karty tytułowej, druga z kart ze środka bloku druku. Badanie polegało na odciśnięciu wilgotnego, sterylnego krążka bibuły o średnicy $4 \mathrm{~cm} \mathrm{z}$ miejsc widocznej działalności mikroorganizmów. Następnie krążki umieszczano na szalkach Petriego o średnicy $9 \mathrm{~cm}$, zawierające pożywkę w ilości $10 \mathrm{~cm}^{3}$, sporządzoną według receptury Czapek-Doxa oraz Sabourauda ${ }^{12}$. Inkubację pobranych prób prowadzono w temperaturze $25^{\circ} \mathrm{C}$ przez $21 \mathrm{dni}$, a następnie oznaczano wyrosłe mikroorganizmy. Optymalny przedział czasowy, po którym grzybnia obrośnie całą szalkę, wynosi 21 dni. Założono również, że jeśli w ciągu siedmiu dni inkubacji powstanie grzybnia o średnicy $3 \mathrm{~cm}$, będzie to oznaczać najwyższy stopień zagrożenia, mówiący o obecności w badanym materiale żywej grzybni. Rozrost grzybni do średnicy $6 \mathrm{~cm}$, uzyskany po 14 dniach inkubacji kwalifikowano jako zagrożenie średnie, które oznacza wykonanie profilaktycznych zabiegów

${ }^{11}$ A. Bakalarz, Zastosowanie epoksykonazolu do dezynfekcji wybranego obiektu XVI-wiecznego pochodzacego z kolekcji Biblioteki fundacji hrokurokuroku Baworowskiego we Lwowie, „Forum Bibliotek Medycznych", 10 (2017) nr 1 (19), s. 244.

${ }^{12}$ O. Fassatiowá, Grzyby mikroskopowe w mikrobiologii technicznej, Warszawa 1983, s. 32. 
dezynfekcyjnych ${ }^{13}$. Niecałkowite i nierównomierne pokrycie szalki żywą grzybnią po 21 dniach inkubacji będzie świadczyć o występowaniu nieaktywnych form zarodnikowych ${ }^{14}$.

Stwierdzono, że zakażenie mikrobami nie jest równomiernie zlokalizowane. Najwięcej kolonii wyrosło na szalkach, w których umieszczono próbki pobrane z wyklejki lub karty tytułowej, a znacznie mniej ze środka bloku książki W pierwszym przypadku stwierdzono 18 wzrostów, a w drugim 8 (tab. 2).

Tabela 2. Liczba zainfekowanych szalek

\begin{tabular}{|l|c|l|}
\hline Miejsce pobrania próbki & $\begin{array}{l}\text { Liczba szalek, na których } \\
\text { wyrosły kolonie }\end{array}$ & $\begin{array}{l}\text { Procentowy udział } \\
\text { szalek zainfekowanych } \\
\text { w odniesieniu do całej } \\
\text { próby [\%] }\end{array}$ \\
\hline Wyklejka lub karta tytułowa & 18 & 30,2 \\
\hline Grzbiet & 15 & 27,5 \\
\hline Przednia okładzina oprawy & 12 & 24,45 \\
\hline Blok książki & 8 & 19,25 \\
\hline
\end{tabular}

Źródło: opracowanie własne.

Otrzymane wyniki potwierdzają fakt, że zakażenie żywą grzybnią jest nierównomiernie zlokalizowane w Biblii. Najwięcej kolonii wyrosło na szalkach z próbek pobranych z wyklejki, karty tytułowej, co potwierdza, że te miejsca są najbardziej narażone na działanie czynników zewnętrznych i sprzyjają rozwojowi. $\mathrm{Z}$ kolei najsłabiej wzrost grzybni zaobserwowano $\mathrm{z}$ na szalkach $\mathrm{z}$ prób pobranych z bloku książki.

Ocena zagrożeń mikrobiologicznych została uzupełniona o jakościową analizę mikroorganizmów. Wyizolowane z książki grzyby zidentyfikowano do gatunku. W badanej kolekcji stwierdzono występowanie Aspergillus Niger van Tieghem (fot. 5).

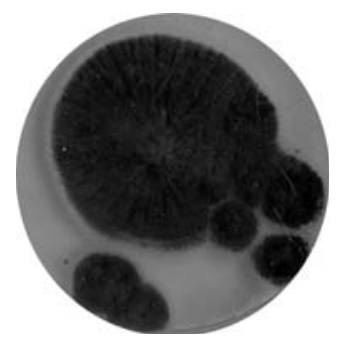

Il. 5. Liniowy wzrost Aspergillus Niger van Tieghem (fot.autora).

${ }^{13}$ Bakalarz, Zastosowanie epoksykonazolu, s. 246.

${ }^{14}$ L. Ogierman, Konserwacja zabytkowego materiału bibliotecznego krakowskich Paulinów na Skatce, Katowice 2005, s. 24. 


\section{Metodyka badań $\mathrm{z}$ zastosowaniem nowych związków pochodnych chinoliny}

Celem badań było syntetyzowanie nowych związków pochodnych chinoliny i wyznaczenie odpowiednich stężeń tych związków do zwalczania zagrożeń mikrobiologicznych występujących w Biblii J. Wujka. Do badań zastosowano pochodne chinoliny, takie jak 4-hydroksy-2-metylochinolinę, 4-chloro-3metylochinolinę, kwas 5-bromo-8-hydroksy-7-karboksychinaldynowy oraz chlorchinaldol $^{15}$.

W celu wyznaczenia współczynnika aktywności przygotowano szereg stężeniowy roztworów w dimetylosulfotlenku, otrzymując odpowiednie stężenia roztworu (według tabeli 3). Roztwory te w objętości $1 \mathrm{~cm}^{3}$ mieszano ze $100 \mathrm{~cm}^{3}$ pożywki, sporządzonej z agaru na brzeczce i wlewano do szalek Petriego. Na zestaloną pożywkę nakładano grzybnię Aspergillus Niger van Tieghem. Liniowy wzrost grzyba kontrolowano co 24 godziny, aż do całkowitego porośnięcia szalki kontrolnej, zawierającej zestaloną pożywkę z $1 \mathrm{~cm}^{3}$ roztworu DMSO. Wyniki aktywności grzybobójczej przedstawiono w tabeli $4 \mathrm{w}$ odniesieniu do związku referencyjnego 4. Wyniki wskazują na wysoką aktywność grzybobójczą pochodnych $1-3^{16}$.

\section{Wyniki badań i dyskusja}

Aktywność grzybobójczą pochodnych chinoliny przedstawiono wobec Aspergillus Niger van Tieghem w formie współczynnika ED50, a uzyskane wyniki zamieszczono w tabeli 3.

Tabela 3. Zestawienie aktywności grzybobójczej związków 1-3 Aspergillus Niger van Tieghem

\begin{tabular}{|c|c|c|c|c|c|c|}
\hline \multirow{2}{*}{$\begin{array}{l}\text { Związek } \\
1\end{array}$} & \multicolumn{6}{|c|}{ Aktywność przeciwgrzybicza Aspergillus Niger van Tieghem } \\
\hline & 2 & 3 & 4 & 5 & 6 & 7 \\
\hline \multirow{2}{*}{$\begin{array}{l}\text { 4-hydroksy-2- } \\
\text { metylochinolina }\end{array}$} & Dawka $[\mathrm{mg} / \mathrm{ml}]$ & 10 & 7,5 & 5 & 2,5 & 1,25 \\
\hline & $\begin{array}{l}\text { Skuteczność inhibicji } \\
{[\%]}\end{array}$ & 100 & 75 & 50 & 25 & 12,5 \\
\hline \multirow[b]{2}{*}{ 4-chloro-3-metylochinolina } & Dawka $[\mathrm{mg} / \mathrm{ml}]$ & 114 & 80 & 50 & 25 & 12,5 \\
\hline & $\begin{array}{l}\text { Skuteczność inhibicji } \\
{[\%]}\end{array}$ & 100 & 75 & 50 & 25 & 12,5 \\
\hline \multirow{2}{*}{$\begin{array}{l}\text { Kwas 5-bromo-8-hydroksy- } \\
\text { 7-karboksychinaldynowy }\end{array}$} & Dawka $[\mathrm{mg} / \mathrm{ml}]$ & & & 60 & 30 & 15 \\
\hline & $\begin{array}{l}\text { Skuteczność } \\
\text { inhibicji[\%] }\end{array}$ & & & 100 & 50 & 15 \\
\hline
\end{tabular}

${ }^{15}$ J. Jampilek i in., Ring-substituted 4-hydroxy-1H-quinolin-2-ones. Preparation and biological activity, „Molecules”, 14 (2009) s. 1145-1159.

${ }^{16}$ Bakalarz, Pochodne chinoliny, s. 172. 


\begin{tabular}{|l|l|c|c|c|c|c|}
\hline \multicolumn{1}{|c|}{$\mathbf{1}$} & \multicolumn{1}{|c|}{$\mathbf{2}$} & $\mathbf{3}$ & $\mathbf{4}$ & $\mathbf{5}$ & $\mathbf{6}$ & $\mathbf{7}$ \\
\hline \multirow{3}{*}{ Chlorochinaldol } & Dawka $[\mathrm{mg} / \mathrm{ml}]$ & 20 & 15 & 10 & & \\
\cline { 2 - 8 } & $\begin{array}{l}\text { Skuteczność inhibicji } \\
{[\%]}\end{array}$ & $<5$ & $<5$ & $<5$ & & \\
\hline \multirow{2}{*}[\mathrm{C}_{3}\mathrm{H}_{7}-\text{Im-Men}]{$^{+}[$Sach $]$} & Dose $[\mathrm{mg} / \mathrm{ml}]$ & 20 & 15 & 10 & & \\
\cline { 2 - 8 } & $\begin{array}{l}\text { Inhibition efficiencies } \\
{[\%]}\end{array}$ & $<5$ & $<5$ & $<5$ & & \\
\hline
\end{tabular}

Źródło: opracowanie własne.

Wykres 1. Porównanie aktywności grzybobójczej związków 1-4 na wybrany rodzaj grzyba

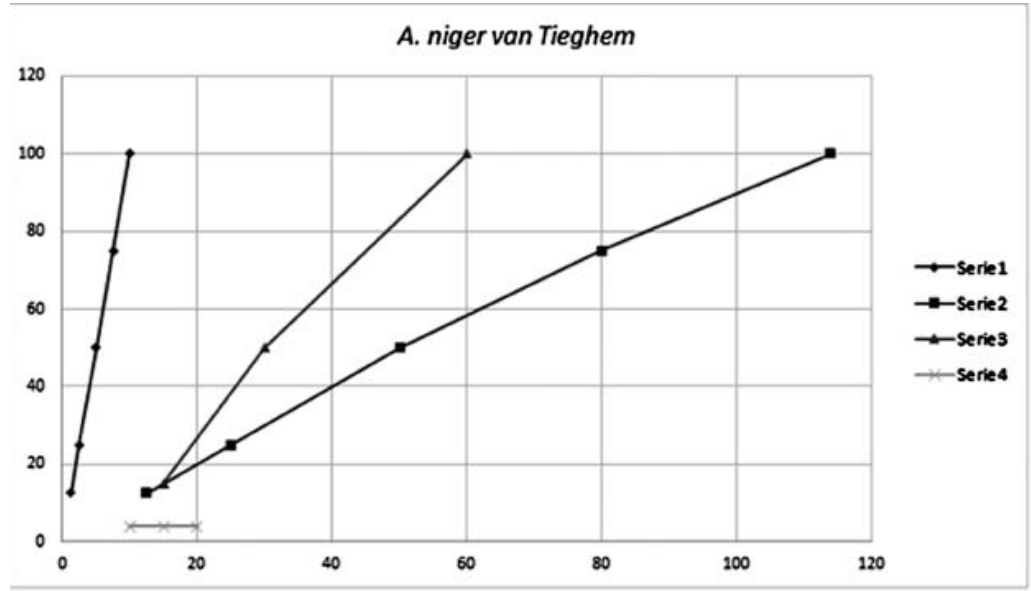

Do wyznaczenia współczynnika ED-50 wykorzystano metodę graficzną Litchfielda i Wilcoxona dla uproszczonej funkcji logarytmiczo-probitowej, ekstrapolując dawkę z punktu na krzywej na poziomie 50\% skuteczności. Zależność skuteczności działania pochodnych chinoliny od zastosowanej dawki przedstawiono na wykresie w stosunku Aspergillus Niger van Tieghem. Korzystając z prezentowanych wykresów odczytano wartość dawki w postaci logarytmicznej, dla której 50\% populacji uległo zniszczeniu.

- Dla związku 4-hydroksy-2-metylochinoliny wynosi ona $0,70 \mathrm{i}$ odpowiada stężeniu $5 \mathrm{mg} / \mathrm{cm}^{3}$ pożywki, która jest naszym wyznaczonym współczynnikiem ED50. Taką dawkę 4-hydroksy-2-metylochinoliny w $100 \mathrm{~cm}^{3}$ pożywki można uzyskać, wprowadzając do niej $1 \mathrm{~cm}^{3}$ roztworu tej substancji w DMSO o stężeniu rzędu $0,004 \%$.

- Dla związku 4-chloro-3-metylochinoliny wynosi ona 1,70 i odpowiada stężeniu $50 \mathrm{mg} / \mathrm{cm}^{3}$ pożywki,którajestnaszym wyznaczonym współczynnikiem ED50. Taką dawkę 4-chloro-3-metylochinoliny w $100 \mathrm{~cm}^{3}$ pożywki można uzyskać, wprowadzając do niej $1 \mathrm{~cm}^{3}$ roztworu tej substancji w DMSO o stężeniu rzędu $0,04 \%$. 
- Dla związku kwasu 5-bromo-8-hydroksy-7-karboksychinaldynowego wynosi ona $1,47 \mathrm{i}$ odpowiada stężeniu $30 \mathrm{mg} / \mathrm{cm}^{3}$ pożywki, która jest naszym wyznaczonym współczynnikiem ED50. Taką dawkę kwasu 5-bromo-8hydroksy-7-karboksychinaldynowego $\mathrm{w} 100 \mathrm{~cm}^{3}$ pożywki można uzyskać, wprowadzając do niej $1 \mathrm{~cm}^{3}$ roztworu tej substancji w DMSO o stężeniu rzędu $0,03 \%$.

\section{Dezynfekcja Biblii}

Do dezynfekcji książki przygotowano następującą mieszaninę: Związki nr 1, 2 i $3 \mathrm{w}$ ilości $300 \mathrm{mg}$ każdy rozpuszczono w $20 \mathrm{ml}$ DMSO, po czym uzupełniono mieszaniną wody $\mathrm{z}$ propanolem $1: 3$ do $100 \mathrm{ml}$. Tak przygotowany preparat nanoszono, stosując metodę przekładek co 20 kartek. Obiekt z przekładkami przechowywano $\mathrm{w}$ szczelnej torbie foliowej $\mathrm{w}$ temperaturze pokojowej przez 7 dni. Po zabiegu zmierzono ponownie $\mathrm{pH}$ papieru. Średnia wartość $\mathrm{pH}$ wynosiła ok. 7,4. Po upływie miesiąca ponownie przeprowadzono badania mikrobiologiczne jak wyżej i zmierzono $\mathrm{pH}$. Po upływie do 21 dni nie stwierdzono wzrostu grzybni ani zmiany $\mathrm{pH}$.

\section{Wnioski końcowe}

Związki pochodne chinoliny to skuteczne, bezpieczne związki w dezynfekcji zbiorów bibliotecznych.

\section{BIBLIOGRAFIA}

\section{Opracowania}

Bakalarz Agnieszka, Pochodne chinoliny jako nowe kolejne $w$ badaniu fungicydy do dezynfekcji materiatów bibliotecznych $i$ archiwalnych, „Forum Bibliotek Medycznych", 10 (2017) nr 2 (20), s. 165-172.

Bakalarz Agnieszka, Zagrożenia mikrobiologiczne zbiorów bibliotecznych, „Nowa Biblioteka", (2014) nr 1 (14), s. 165-170.

Bakalarz Agnieszka, Zastosowanie epoksykonazolu do dezynfekcji wybranego obiektu XVI-wiecznego pochodzacego z kolekcji Biblioteki fundacji hroku Baworowskiego we Lwowie, ,,Forum Bibliotek Medycznych”, 10 (2017) nr 1 (19), s. 244, 246.

Fassatiowá Olga, Grzyby mikroskopowe w mikrobiologii technicznej, Warszawa 1983. pilek Josef i in., Ring-substituted 4-hydroxy-1H-quinolin-2-ones. Preparation and biological activity, „Molecules”, 14 (2009) s. 1145-1159.

Kossowska Maria, Biblia w języku polskim, t. 1, Poznań 1968.

Ogierman Leonard, Konserwacja zabytkowego materiału bibliotecznego krakowskich paulinów na Skatce. Katowice 2005.

Uchański Jakub, Obecny stan badań nad życiem J. Wujka, „Polonia Sacra” (1950) z. 1-4.

\section{Netografia}

Biblia Jakuba Wujka, https://pl.wikipedia.org/wiki/Biblia_Jakuba_Wujka/(dostęp 23.06.2019). Biblia Jakuba Wujka, http://biblia.tm.pl/biblia_jakuba_wujka.html/ (dostęp 23.06.2019). 
Biblia Szymona Budnego, (http://biblia.tm.pl/biblia_szymona_budnego.html/ (dostęp 23.06.2019).

Jakub Wujek, https://pl.wikipedia.org/wiki/Jakub_Wujek/ (dostęp 23.06.2019).

Majewski Marcin, Jak przekłady zmieniaja sens Biblii... O teorii i praktyce ttumaczenia Biblii, https://upjp2.academia.edu/MarcinMajewski/ (dostęp 23.06.2019).

\title{
THE USE OF QUINOLINE DERIVATIVES FOR DISINFECTION OF BIBLICAL PRINTS FROM THE COLLECTION OF THE WIKTOR H. BAWOROWSKI FOUNDATION LIBRARY IN LVIV
}

\begin{abstract}
Summary
Microbiological tests and disinfection were carried out on the 16th-century Bible published by Jakub Wujek according to the CT II reference number 75938 from the Library of the Victor Wiktor Foundation in Lviv. Jakub Wujek was a Polish clergyman, a Jesuit, doctor of theology, rector of the Vilnius Academy. His translation of the Bible into Polish began in 1584-1595 and was published in its entirety in 1599. During the lifetime of Wujek only the New Testament and Psalter (1594) went out. The Old Testament was ready in 1596. Wujek died in Kraków on July 27, 1597, and the Bible appeared only on August 25, 1599, because Grodzicki together with the appointed commission led to changes in the text of the translation. Due to various circumstances and difficulties, Wujek's work remained in the Catholic Church the most important translation of the Bible for over 350 years. Prior to the microbiological tests, paper $\mathrm{pH}$ tests were performed, counting every third card and examined at three points. The value of the measured $\mathrm{pH}$ indicates low acidification. Microbiological tests were carried out and it was found that the microbial infection is not evenly located. Most colonies grew on the dishes in which samples taken from the sticker or the title card were placed, and much less from the center of the book block. The assessment of microbiological hazards has been supplemented with a qualitative analysis of microorganisms. Mushrooms isolated from the book have been identified to the species. Aspergillus Niger van Tieghem was found in the study collection. The aim of the study was to synthesize new quinolinederived compounds and to determine appropriate concentrations of these compounds to combat the microbiological hazards occurring in the Jakub Wujek Bible. In order to determine the activity coefficient a concentration range of solutions in dimethylsulfoxide was prepared to obtain the appropriate concentration of the solution. Linear growth of the fungus was controlled every 24 hours until the control pan containing the solidified medium from $1 \mathrm{~cm}^{3}$ of DMSO solution was completely overgrown. The dependence of the effectiveness of quinoline derivatives on the dose used is shown in the graph in the Aspergillus Niger van Tieghem ratio. A mixture for disinfecting the book was prepared. Quinoline derivatives are effective, safe compounds in the disinfection of library collections.
\end{abstract}

Key words: bible; disinfection; new relationships; conservation; harvest protection 